\title{
Induction of Complete Regressions of Oncogene-induced Breast Tumors in Mice
}

\author{
R. Benezra, * E. Henke, * A. Ciarrocchi, ${ }^{*}$ M. Ruzinova, ${ }^{*}$ D. Solit, ${ }^{\text {II }}$ N. Rosen, $\dagger$ \\ D. Nolan, ${ }^{\mathscr{T}}$ V. MitTal, ${ }^{\text {TI }}$ and P. DE CANDiA* \\ Departments of ${ }^{*}$ Cancer Biology and Genetics, $†$ Experimental Therapeutics, and "Medicine, \\ Memorial Sloan-Kettering Cancer Center, New York 10021; "Cold Spring Harbor Laboratory, \\ Cold Spring Harbor, New York 11724
}

\begin{abstract}
Over the past decade, mouse models of cancer have come to resemble human disease much more closely than simple subcutaneous or orthotopic systems. Intervention strategies that work on these new model systems are more likely to have an impact clinically. We have shown recently that antiangiogenic stress imposed by loss of Id protein in endothelial progenitor cells results in dramatic central necrosis in breast tumors initiated in mice by overexpression of the her $2 /$ neu oncogene. Tumor cells remain viable at the periphery, perhaps via the hypoxic response pathway which allows the lesions to expand. Inhibition of this pathway by the inactivation of the Hif- $1 \alpha$ chaperone Hsp90 in combination with antiangiogenic stress leads to the first reported complete regression of these aggressive breast tumors.
\end{abstract}

Over the past 20 years, we have learned more about the molecular events leading to cancer than we have in all time preceding. Detailed descriptions of the signaling pathways that have gone awry in the tumor cell and the tumor microenvironment have increased our understanding of the cancer process in dramatic ways. Even a decade ago, at the last Cold Spring Harbor Symposium that focused on cancer, the progress we have seen to date in exploiting this information for the development of targeted therapeutics could not have even been wistfully imagined. As we trumpet our success with Gleevec, for example (see Sawyers, this volume), in managing chronic myelogenous leukemia by inhibiting the enzyme (bcr-abl) that causes it, we are reminded by the lay press and public, perhaps justifiably so, that far too many more people are still dying of cancer than one might have hoped, given the enormous investment we have made in controlling cancer over the past century. But there is one point which is generally overlooked. We as cancer biologists are excited less by the progress made to date than by the rate of increase of new and profound discoveries that are now being made. Although we recognize with deep sadness that we cannot immediately translate this work to help those around us who are suffering from this disease, we sense with profound anticipation that our current work will affect the lives and health of generations to come. We are indeed in the midst of a revolution in cancer biology that only the most myopic among us can possibly fail to see.

How do we speed the translation of our new-found knowledge into effective, nontoxic cancer therapies? One thing that has become abundantly clear is that physiologically relevant mouse models of human cancer, in which oncogenes are overexpressed or tumor suppressor genes are inactivated in adult animals, hold great promise in exploring the mechanistic basis of cancer initiation and progression, as well as therapeutic approaches likely to be meaningful clinically. It is one thing to cure a mouse of a tumor grown under the skin or even orthotopically, but quite another to eliminate aggressive spontaneous tumors in these animals. As Tyler Jacks so poignantly stated after showing a slide of an aggressive K-ras-induced lung tumor, "Cure this."

We have taken up this challenge by trying to induce complete regressions of mammary tumors in mice that result from overexpression of the her2/neu oncogene (Guy et al. 1992), an oncogene that is overexpressed in approximately $30 \%$ of human breast cancers. The lesions arise in these mice with about a 4-month latency and appear as multifocal, dense cellular masses which kill their host within about 7-8 months with close to $100 \%$ penetrance. A variety of chemotherapeutic approaches have at best delayed the time to progression of these tumors, with no complete regressions reported to date (Sacco et al. 1996; Shah et al. 1999; Anisimov et al. 2002; Manor et al. 2003).

The strategy we have taken to treat these mice is based on our analysis of Id protein loss in the vessels of tumor xenografts. The Id proteins are a set of four highly related proteins (called Id1-4) which act as naturally occurring dominant negative antagonists of basic helix-loop-helix (bHLH) transcription factors (Ruzinova and Benezra 2003; Perk et al. 2005). They contain the HLH dimerization motif but are missing the basic region which contacts DNA; therefore, heterodimers between Ids and bHLH proteins fail to bind DNA or to activate transcription (see Fig. 1). The Id proteins are expressed at high levels through mid-gestation in a broad but complex spatio-temporal pattern and are dramatically down-regulated late in development and postnatally (Jen et al. 1996, 1997). By and large, their expression is enriched in highly proliferative, undifferentiated cells in various cell lineages, and their loss is associated with alteration in cell fate, often toward a fully differentiated postmitotic state (although there are exceptions). The expression pattern and biochemical activity of Id 1 and Id 3 are nearly identical, and indeed, only when copies of both Id1 and Id 3 are disrupted in animals do the most severe phenotypes mani- 

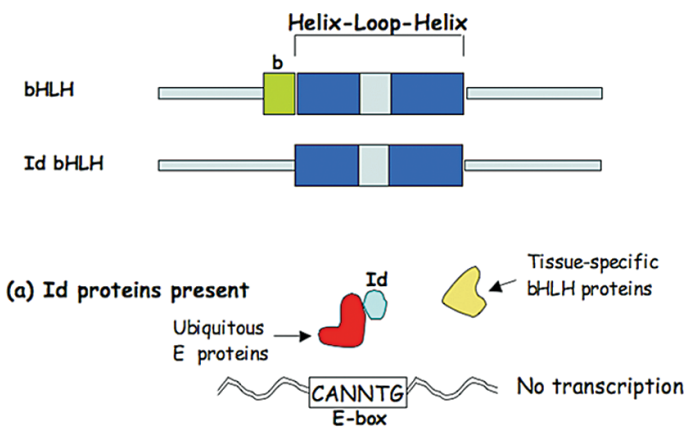

(b) Id proteins absent

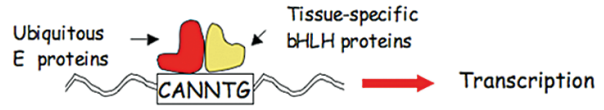

Figure 1. Mechanism of Id action. The Id proteins act as naturally occurring dominant negative antagonists of the basic helixloop-helix (bHLH) transcription factor family. Id proteins contain the HLH dimerization motif but lack the basic region that contacts DNA. Heterodimers between Id and other members of the family therefore fail to bind DNA. The preferred targets of the Id proteins in the cell are the ubiquitously expressed E proteins, which are themselves obligate heterodimerizing partners of tissue-specific bHLH proteins such as MyoD and NeuroD. Thus, by sequestering E proteins, Id can control tissue-specific gene expression in multiple cell lineages using the same biochemical mechanism. For more detailed review, see Ruzinova and Benezra (2003) and Perk et al. (2005).

fest: premature neural differentiation, hemorrhage in the forebrain, ventricular-septal cardiac defects, and embryonic lethality (Lyden et al. 1999; Fraidenraich et al. 2004). The hemorrhage in the forebrain turned out to be a defect in angiogenesis, and this led us to test whether postnatal tumor angiogenesis was affected in adult animals missing 1-3 copies of the Id1,3 pair. Indeed, reduced Id dosages led to a profound defect in tumor an- giogenesis in subcutaneous tumors initiated with either B6Rv2 lymphoma cells or a breast cancer cell line (Lyden et al. 1999). These effects were associated with the appearance of stunted and occluded blood vessels and an increase in hemorrhage in these tumors. Lewis lung carcinoma cells, however, produced subcutaneous lesions that continued to expand in the reduced Id backgrounds despite the loss of vascular integrity and an increase in hemorrhage and necrosis. Remarkably, however, despite the growth of the primary lesion, metastasis was dramatically reduced in the Id knockout strains, clearly indicating a difference in Id-dependence in the growth of xenografts and metastatic lesions.

We went on to show that the defect in the animals with reduced Id dosages could be traced to failure to mobilize endothelial cell progenitors to the site of the tumor (Lyden et al. 2001). Id1 levels rise in the bone marrow in response to VEGF, and this expression appears to be essential for the migration of EPCs from the marrow into the periphery and to the site of the tumor. The Id-dependent steps in this pathway are not yet known. Once at the site of the tumor, Id appears to be required for the maintenance of expression of genes involved in a promigratory pathway that may be essential for the formation of a functional vascular network. Integrins $\alpha 6$ and $\beta 4$, FGFR1, MMP2, and laminin 5 have been observed to be significantly down-regulated in Id-deficient endothelial cells at the site of the tumor (Ruzinova et al. 2003). FGFR1 activated by FGF2 up-regulates and enhances secretion of MMP2. MMP2 in turn converts laminin 5 in a proteolytic fragment, which engages $\alpha 6 \beta 4$ integrins, stimulating the endothelial cell migration (see Fig. 2) (Klein et al. 1993; Giannelli et al. 1997; Pfeifer et al. 2000). Inhibition of single components of the described pathway in matrigel plug assays is sufficient to partially phenocopy Id loss, thereby adding functional significance to the array results. Importantly, this model has received support from

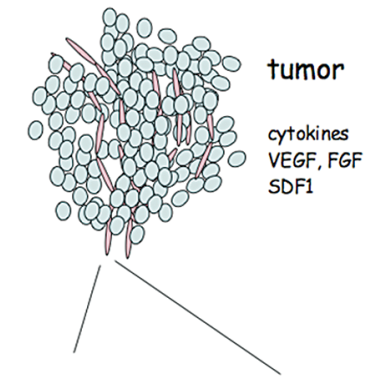

tumor endothelial cell

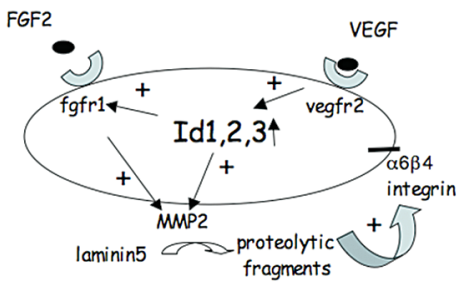

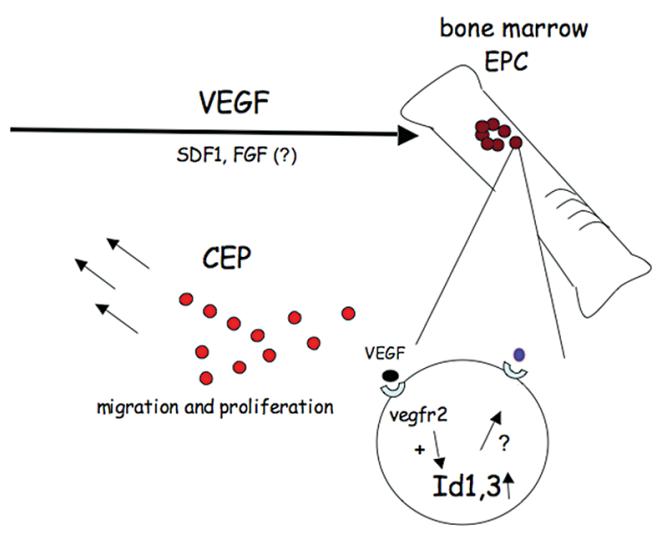

migration and proliferation
Figure 2. Id proteins in peripheral and bone marrow-derived endothelial cells. In the periphery, Ids are required for maintaining the expression of Fgfr1, MMP2, laminin 5, and $\alpha 6 \beta 4$ integrin, which form a promigratory network. This network depends on the engagement of $\alpha 6 \beta 4$ integrin with an MMP2 cleavage product of laminin 5 . In the bone marrow, Ids are required for the mobilization and proliferation of endothelial progenitor cells (EPCs) which enter the bloodstream as circulating endothelial progenitors (CEP) and migrate to the site of the tumor. Id1 and Id 3 in the bone marrow are upregulated in response to VEGF, and this up-regulation is required for mobilization. The downstream consequences of Id expression in the bone marrow are still not well understood. (Reproduced, with permission, from Perk et al. 2005 [@Macmillan Magazines;].) 
an independent genetic analysis where it was shown that hypomorphic mutations in $\beta 4$ integrin also lead to impaired angiogenesis (Nikolopoulos et al. 2004).

To determine whether Id loss is worth pursuing clinically, it was important to monitor the effects of Id loss on tumors other than xenografts. Tumors that arise as a result of the overexpression of oncogenes or loss of tumor suppressor genes are much more similar pathophysiologically to human disease than tumors that arise from the inoculation of tumor cells subcutaneously. In addition, xenografts have been "cured" with therapeutic approaches that have not fared well in the clinic. However, if a spontaneous tumor model can be brought into complete remission with a treatment regimen, it seems likely that such treatments will have a higher chance of being effective in the clinic. This paper details our success at bringing an aggressive her2/neu-induced mammary carcinoma into complete remission with a combination of Id loss and targeting of the Hsp90 stress response pathway.

\section{THE CROSS}

To determine whether a reduction in Id 1 or Id 3 expression prevents or alters the rate of spontaneous mammary tumor formation in neu transgenic mice, we bred mice overexpressing the her2/neu oncogene (YD allele) in the mammary epithelia (using the mouse mammary tumor virus long terminal repeat [MMTV-LTR]) with $\mathrm{Id}^{-/} \mathrm{Id}^{+/-}$mice. HER $2 /$ neu encodes a transmembrane tyrosine kinase that is commonly amplified in human breast tumors. Amplification of HER2 correlates with a poor clinical prognosis in breast cancer patients (Slamon et al. 1987), and anti-Her2 antibodies have therapeutic utility in this disease (Slamon et al. 2001; Baselga et al. 2002; Vogel et al. 2002). Mice expressing neu under the transcriptional control of the MMTV-LTR develop mammary tumors after a prolonged latency (Guy et al. 1992). YD mice express a neu receptor with a 12-amino acid deletion in the extracellular domain that leads to its constitutive dimerization and activation. In addition, four of the five tyrosine phosphorylation sites have been mutated to phenylalanine in the YD neu protein, which retains only the fourth ("D") site that binds to Shc when phosphorylated. These mice demonstrate accelerated formation of multifocal solid comedo-type tumors with low metastatic potential (Dankort et al. 2001). Throughout this paper we refer to the Id-deficient populations as missing one, two, or three copies of Id genes, and we do not distinguish between Id1 and Id3. This simplification is possible because no phenotypic differences were observed among Id1- and Id3-deficient mice. Id wild-type, YD neu mice developed their first mammary lesion with a mean latency of 193 days $(n=34)$ (de Candia et al. 2003). In Id-deficient mice, tumor onset was not delayed (mean tumor latency of 170 days $[n=82], 159$ days $[n=$ $67]$, and 178 days $[n=23]$ ) in mice missing one, two, or three copies of Id 1 or Id3 (de Candia et al. 2003).

Tumor-bearing mice were sacrificed 8 weeks after detection of the first lesion. At sacrifice, tumors were classified as solid if more than $90 \%$ of the tumor volume was

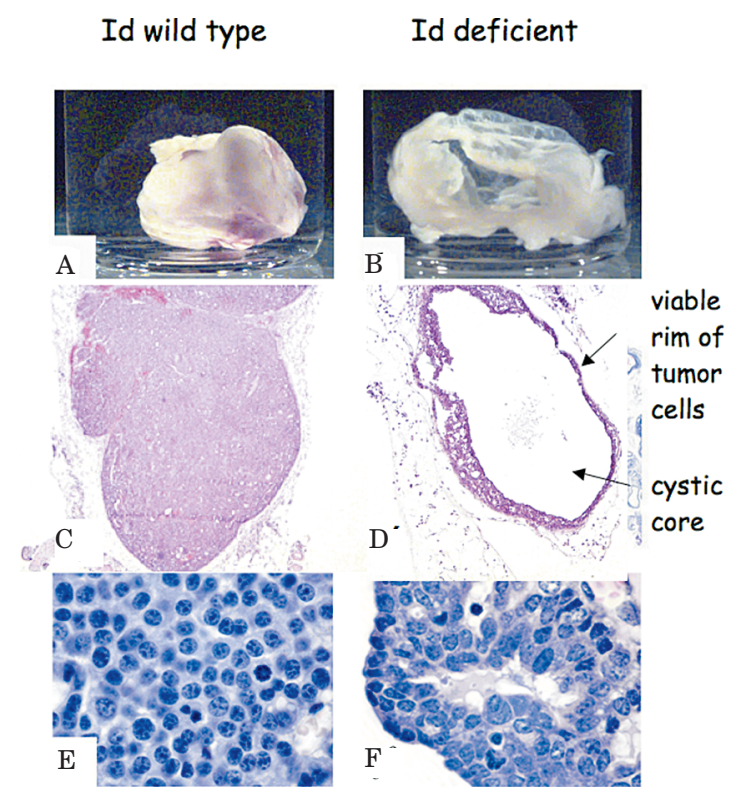

Figure 3. Mammary tumors arising in YD neu Id-deficient mice were cystic with a small rim of viable cells surrounding an acellular core. $(A, B)$ Tumors dissected from a YD neu $\mathrm{Id}^{+/+} \mathrm{Id} 3^{+/+}$ mouse $(a)$ and from a YD neu $\mathrm{Id}^{-/-} \mathrm{Id}^{+/-}$mouse $(B) .(C, E)$ $\mathrm{H} \& \mathrm{E}$ staining of the $\mathrm{YD}$ neu $\mathrm{Id} 1^{+/+} \mathrm{Id}_{3} 3^{+/+}$tumor seen in $A$. $(D, F)$ H\&E staining of the YD neu $\mathrm{Id}^{-1-} \mathrm{Id}^{+/-}$tumor seen in $b$. (Reprinted, with permission, from de Candia et al. 2003 [@National Academy of Sciences].)

grossly viable, and cystic if more than $90 \%$ of the tumor volume consisted of necrotic or cystic components. Heterogeneous tumors were those that did not meet the criteria for either solid or cystic. The majority of tumors that developed in the Id wild-type mice were entirely solid (53\%), with only minimal gross evidence of necrosis. In a subset of Id wild-type tumors, heterogeneous $(23.5 \%)$ or cystic $(23.5 \%)$ architecture was observed. In the Id-deficient mice, a significantly larger proportion of tumors were cystic in appearance $(64.5 \%, 56.5 \%$, and $63 \%$, respectively, in the mice deficient in one, two, or three copies of Id).

On histological examination, the cystic lesions in Iddeficient mice consisted of a narrow rim of viable tumor cells surrounding a core of hemorrhagic fluid (Fig. 3). The morphology of the tumor cells in the viable component of the cystic lesions was similar to that observed in solid tumors. In both instances, the tumor cells were anaplastic with a complete loss of glandular morphology, a high nuclear/cytoplasmic ratio, and frequent signs of extracellular matrix invasion. Importantly, this type of "hollowing-out" of the central portion of a tumor has been observed in another antiangiogenic setting: A synovial sarcoma patient treated with the monoclonal antibody against VEGF-A (Avastin/Bevicizumab) shows a response remarkably similar to that observed in the mammary tumors developing in the reduced Id background (D. D'Adamo, pers. comm.). Increased central necrosis of a solid tumor in response to antiangiogenic stress may prove to be a general phenomenon both in animal models and in the clinic. 


\section{Abnormal Vascularization of Id-deficient Tumors}

We visualized YD neu tumor infiltrating vessels by performing in situ hybridization with a marker for tumor endothelium, angiopoietin 2 (Maisonpierre et al. 1997). In cystic tumors, vessels were present in the adjacent extracellular matrix, but only very sporadically inside the thin rim of tumor cells (data not shown). As above, a subset of tumors in the Id-deficient background were solid. In these tumors, we observed abnormal vascularization: Tumor vessels were dilated and twisted and had significantly more anastomoses as compared to their Id wildtype counterparts (de Candia et al. 2003). This pattern has also been observed in the blood vessels of $\mathrm{Id}^{-/} \mathrm{Id}^{-/-}$ embryos, and more recently in lymphoid lesions of PTEN $^{+/} \mathrm{Id}^{-/-}$animals (Ruzinova and Benezra 2003).

We believe the effects of Id1 and Id3 loss are primarily on the vasculature, since Id1,3 expression, as monitored by antibodies monospecific for Id 1 or Id 3 and showing no staining in the appropriate Id knockout animals, is confined to the vasculature (de Candia et al. 2003). Indeed, human samples also show little Id1 protein staining in approximately 50 tumor samples of all stages and grades. Rare positive cells in any of these lesions cannot be ruled out, however.

\section{Evidence of Hypoxia in Small Id-deficient Tumors}

HIF-1 (hypoxia-inducible factor 1) is a heterodimeric transcription factor regulated by oxygen concentration. The HIF-1 $\alpha$ component of the heterodimer cannot be detected in normoxic cells given its continuous degradation via ubiquitination, while it is strongly induced by hypoxia (Huang et al. 1998). We analyzed the expression of HIF- $1 \alpha$ by immunohistochemistry in Id wild-type and -deficient YD neu tumors. When we stained small lesions $(<0.5 \mathrm{~cm}$ diameter $)$ in which the formation of a cystic cavity had not yet occurred, we observed that none $(0 / 12)$ of wild-type lesions expressed Hif-1 $\alpha$, while $50 \%(6 / 12)$ of the Id-deficient lesions showed a strong induction of Hif- $1 \alpha$ (de Candia et al. 2003). Thus, small tumors in Iddeficient mice seem to be hypoxic as compared to tumors that arise in wild-type background. Once the solid or cystic lesions became larger $(>1.5 \mathrm{~cm}$ diameter) Hif- $1 \alpha$ was consistently expressed in association with areas of necrosis in Id wild-type and -deficient mice. Interestingly, in the large cystic tumors, the cells in the rim did not express Hif- $1 \alpha$. Thus, these cells do not seem to be hypoxic.

\section{INTERPRETATION AND STRATEGY}

The similarity between the effects of Avastin on a solid tumor and loss of Id, i.e. an increase in central necrosis surrounded by a viable rim of cells, leads one to believe that this may be a general consequence of antiangiogenic stress and therefore worthy of further investigation. Indeed, as reported in this volume, another anti-VEGF strategy known as the VEGF trap, which employs a soluble VEGF receptor fragment to sequester free VEGF in the periphery, also leads to a similar effect (see Yancopoulos, this volume). This leads to the next obvious question of how to inhibit the viable rim of cells and to effect a more complete regression of these lesions.

Oncologists have noted that killing the central core of a tumor with chemotherapeutics is more difficult than hitting the rim. Perhaps then a combination of chemotherapy plus antiangiogenic stress would show synergistic effects in eradicating the her $2 /$ neu-driven breast tumors. But what agent to choose? It seemed reasonable to assume that the dramatic up-regulation of Hif- $1 \alpha$ we observed in the early lesions in the Id knockout backgrounds was an important "bypass" step being utilized by the viable rim to recruit or co-opt local vessels. Targeting this step seemed like a good choice. Fortunately, we had at our disposal a compound called 17-AAG, a derivative of geldanamycin which, by inhibiting the chaperone Hsp90, leads to the degradation of client proteins, one of which is Hif- $1 \alpha$ (Mabjeesh et al. 2002). Another protein that is rapidly turned over after Hsp90 inhibition is her2/neu, the oncogene driving the growth of the lesion in the first place. Although the effects on other Hsp90 client proteins could clearly have other unwanted effects, we were encouraged that 17-AAG had been reported as having some antitumor effects on its own in other settings (Neckers 2002; Solit et al. 2002). We proposed therefore that combination of Id loss and administration of 17-AAG to inhibit the Hif- $1 \alpha$ bypass pathway would be a more effective strategy than either treatment alone in the management of the transgene-induced mammary carcinomas.

\section{INDUCTION OF COMPLETE REGRESSIONS}

YD mice in an Id wild-type or knockout background were treated with $17 \mathrm{mg} / \mathrm{kg}$ 17-AAG for 3 consecutive days each week for 8 weeks. Following 8 weeks of therapy, the treatment in Id wild-type mice caused only a modest growth inhibition of $48 \%$ (mean tumor volume of $2270 \mathrm{~mm}^{3}$ in vehicle-treated mice vs. $1189 \mathrm{~mm}^{3}$ in 17 AAG-treated, $p=0.09$ ). The growth inhibitory activity of 17-AAG was dramatically enhanced to $96 \%$ inhibition in Id-deficient mice (mean tumor volume of $3863 \mathrm{~mm}^{3}$ in vehicle-treated mice vs. $138 \mathrm{~mm}^{3}$ in 17-AAG-treated, $p=$ 0.0002) (Fig. 4). With discontinuation of 17-AAG, tumor progression was observed in all mice (Fig. 4), indicating that the effect of the therapy was cytostatic and not cytotoxic in this particular regimen (see also Conclusions).

In wild-type or Id-deficient solid tumors removed from vehicle-alone-treated mice and from Id wild-type 17AAG-treated unresponsive mice, the viable portion of the tumors consisted of homogeneous sheets of tumor cells (de Candia et al. 2003). Cells in the centers were typically quiescent while those at the periphery demonstrated a high proliferative index. Apoptotic cells were infrequent and scattered without clear pattern (not shown). In the EPL (vehicle-alone)-treated cystic tumors, the cells composing the viable rim were similarly homogeneous and possessed a high proliferative index (data not shown). In contrast, in 7 of 11 17-AAG-treated tumors, a glandular morphology was observed (4 of 4 Id-deficient tumors and 3 of 7 Id wild-type tumors). These tumors had a lower nuclear to cytoplasmic ratio, an absence of mitotic figures, and a low proliferative index. Together then, these results 

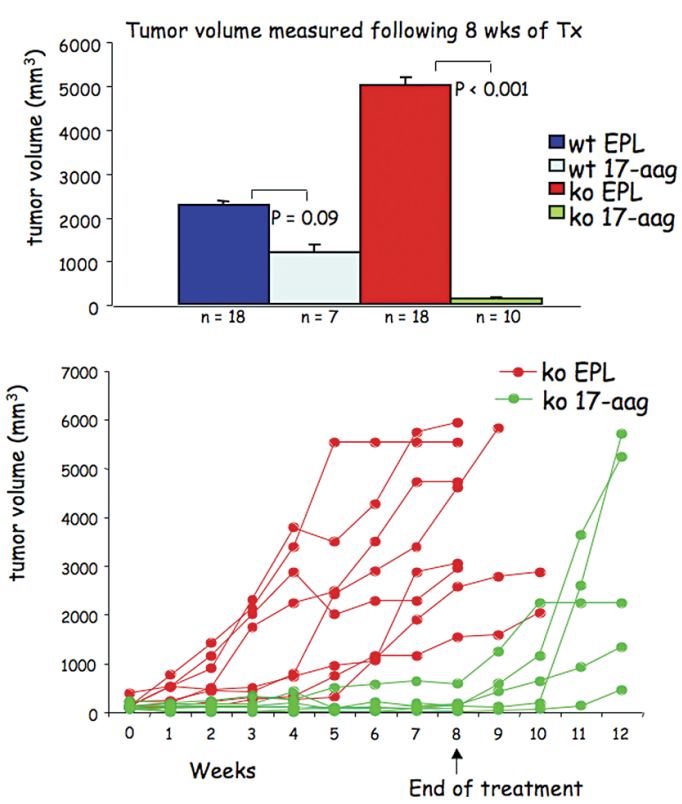

Figure 4. Induction of complete tumor regressions. (Top) Mean tumor volume in Id wild-type or Id-deficient animals following 8 weeks of treatment with $17-\mathrm{AAG} 75 \mathrm{mg} / \mathrm{kg}$ or EPL vehicle only as control. 17-AAG was significantly more effective in YD neu Id-deficient mice (two copies missing) than in Id wt mice. Error bars, S.E. (Bottom) Following discontinuation of treatment, tumor regrowth was observed in all mice (each line represents change in tumor volume over time of an individual YD neu Id-deficient mouse treated with 17-AAG or EPL vehicle only as control). (Reprinted, with permission, from de Candia et al. 2003 [@National Academy of Sciences].)

suggest that 17-AAG has an effect on the differentiation status of the cell, regardless of the Id genotype, but that the consequence of this effect, in addition to any effect due to inhibition of the Hif- $1 \alpha$ bypass pathway, leads to more profound growth inhibition when antiangiogenic stress is imposed on the system by loss of Id expression.

\section{CONCLUSIONS}

It has been several decades since the Judah Folkman hypothesis, elegant in its simplicity: Tumors should not be able to grow beyond a very limited size if the microvessel density is held low enough, and therefore, antiangiogenic stress should be an effective anticancer strategy. This notion, coupled with the known genetic stability of the targeted endothelial cells, led the way for the development of the new generation of antiangiogenic therapies that are now working their way into the clinic. It is important to note that this strategy went through the so-called "glitter-to-ashes" syndrome familiar to many of us in which early clinical stumbles in a novel area lead the lay press to conclude that this will never work. The technology is perceived as another example of scientists overselling their own ideas or findings, and droves begin jumping off the bandwagon. But this is just when the serious science begins. Indeed, the resurrection of the antiangiogenic approach is in full force with the recent approval of Avastin, shown, in combination with chemotherapy, to extend the lives of patients with ad- vanced colorectal carcinoma.

Avastin will clearly not be the end of the story, however. New targets and new therapeutics are likely to follow based on the exciting science emerging from many laboratories. Indeed, there are indications from a number of preclinical studies that anti-VEGF stress and antiangiogenic stress in general will need to be supplemented with other therapies, since some tumors can find effective bypass pathways when faced with extreme hypoxia. Loss of $\mathrm{p} 53$, for example, has been shown to increase the resistance of tumors to antiangiogenic intervention ( $\mathrm{Yu}$ et al. 2002), presumably by short-circuiting the apoptosis program. Tumors treated with a VEGF trap have severe microvessel density reductions but manage to co-opt local vessels at the periphery. Thus, as one might have expected on the basis of the treatment of other complex diseases, combination therapies targeting multiple points of vulnerability (the vasculature, the cell, and perhaps other components of the stroma) will be most effective in controlling cancer in human populations.

We have been modeling the effects of antiangiogenic intervention using mouse models of human cancer. As has become abundantly clear, mouse models in which oncogenes or tumor suppressor genes are misregulated (either constitutively through development or acutely in adult animals) generate cancers that are pathophysiologically very similar to human disease and are therefore more likely than subcutaneous tumors to accurately predict the course of any given intervention. We have shown that genetic inactivation of members of a gene family (Ids) essential for the mobilization, recruitment, and maturation of endothelial cells at the site of a tumor leads to severe antiangiogenic stress. The consequence of such stress on breast tumors induced by constitutive overexpression of the her $2 /$ neu oncogene in the mammary epithelia is a dramatic increase in hypoxia, which is followed by the cystification of the core of lesion but survival of a viable rim of cells at the periphery of the tumor. Subcutaneous breast tumors, on the other hand, show complete regressions in the Id-reduced background. It should be noted, however, that the Lewis lung carcinoma cells injected subcutaneously did show an ability to expand despite extensive hypoxia and necrosis, the first indication of an operational bypass pathway for tumors faced with Id reductions in the endothelium. In other spontaneous tumor model systems, we have shown that in response to reduced Id dosages, some cancers completely regress (intrauterine tumors in $\mathrm{Pten}^{+/}$animals) (Ruzinova et al. 2003) and some tumors show effects that are tumor-grade-dependent (prostate tumors in TRAMP mice) (Li et al. 2004).

How do we treat the tumors that respond to antiangiogenic stress but continue to expand around the centrally necrotic core? The dramatic increase in Hif- $1 \alpha$ staining in the early breast lesions in the Id 1 knockout mice suggested that the Hif- $1 \alpha$ hypoxia response pathway may be the mechanism of bypass. Hsp90 has been shown to be required for the proper folding and stability of Hif- $1 \alpha$ (as well as other proteins, including her $2 / \mathrm{neu}$ ). Administration of the Hsp90 inhibitor (17-AAG) to the MMTVher2/neu Id knockout mice (but not mice with normal tu- 
mor angiogenesis) led to the complete regression of these aggressive breast lesions. To our knowledge, this is the first complete remission ever induced in these animals. Importantly, however, when 17-AAG is removed after 8 weeks of treatment, the tumors reappear and begin growing rapidly, indicating that the therapy is cytostatic and not cytotoxic. Whether more prolonged administration of the drug to the Id knockout animals ever leads to a permanent "cure" is worthy of exploration. In any event, these animals should provide a valuable model for tumor dormancy, a problem of great clinical importance.

In summary, physiologically relevant mouse models of cancer will be important predictors of clinical efficacy of various targeted strategies. Biologists have spent the last 20 years defining the important targets in the cancer cell and its microenvironment. Through the use of spontaneous mouse tumor models, we will learn how to hit these targets effectively.

\section{ACKNOWLEDGMENTS}

This work was supported by grants from the National Institutes of Health (R.B., V.M.), American-Italian Cancer Foundation (P.d.C., A.C.), Goodwin Experimental Therapeutics (E.H., R.B.), and the Breast Cancer Research Foundation (R.B.).

\section{REFERENCES}

Anisimov V.N., Khavinsov V., Alimova I.N., Provintsiali M., Manchini R., and Francheski K. 2002. Epithalon inhibits tumor growth and expression of HER-2/neu oncogene in breast tumors in transgenic mice characterized by accelerated aging. Bull. Exp. Biol. Med. 133: 167.

Baselga J., Rischin D., Ranson M., Calvert H., Raymond E., Kieback D.G., Kaye S.B., Gianni L., Harris A., Bjork T., Averbuch S.D., Feyereislova A., Swaisland H., Rojo F., and Albanell J. 2002. Phase I safety, pharmacokinetic, and pharmacodynamic trial of ZD1839, a selective oral epidermal growth factor receptor tyrosine kinase inhibitor, in patients with five selected solid tumor types. J. Clin. Oncol. 20: 4292.

Dankort D., Maslikowski B., Warner N., Kanno N., Kim H., Wang Z., Moran M.F., Oshima R.G., Cardiff R.D., and Muller W.J. 2001. Grb2 and Shc adapter proteins play distinct roles in Neu (ErbB-2)-induced mammary tumorigenesis: Implications for human breast cancer. Mol. Cell. Biol. 21: 1540 .

de Candia P., Solit D.B., Giri D., Brogi E., Siegel P.M., Olshen A.B., Muller W.J., Rosen N., and Benezra R. 2003. Angiogenesis impairment in Id-deficient mice cooperates with an Hsp90 inhibitor to completely suppress HER2/neu-dependent breast tumors. Proc. Natl. Acad. Sci. 100: 12337.

Fraidenraich D., Stillwell E., Romero E., Wilkes D., Manova K., Basson C.T., and Benezra R. 2004. Rescue of cardiac defects in id knockout embryos by injection of embryonic stem cells. Science 306: 247.

Giannelli G., Falk-Marzillier J., Schiraldi O., Stetler-Stevenson W.G., and Quaranta V. 1997. Induction of cell migration by matrix metalloprotease-2 cleavage of laminin-5. Science 277: 225.

Guy C.T., Webster M.A., Schaller M., Parsons T.J., Cardiff R.D., and Muller W.J. 1992. Expression of the neu protooncogene in the mammary epithelium of transgenic mice induces metastatic disease. Proc. Natl. Acad. Sci. 89: 10578.

Huang L.E., Gu J., Schau M., and Bunn H.F. 1998. Regulation of hypoxia-inducible factor 1alpha is mediated by an O2-dependent degradation domain via the ubiquitin-proteasome pathway. Proc. Natl. Acad. Sci. 95: 7987.
Jen Y., Manova K., and Benezra R. 1996. Expression patterns of Id1, Id2, and Id 3 are highly related but distinct from that of Id4 during mouse embryogenesis. Dev. Dyn. 207: 235.

-1997. Each member of the Id gene family exhibits a unique expression pattern in mouse gastrulation and neurogenesis. Dev. Dyn. 208: 92.

Klein S., Giancotti F.G., Presta M., Albelda S.M., Buck C.A., and Rifkin D.B. 1993. Basic fibroblast growth factor modulates integrin expression in microvascular endothelial cells. Mol. Biol. Cell 4: 973.

Li H., Gerald W.L., and Benezra R. 2004. Utilization of bone marrow-derived endothelial cell precursors in spontaneous prostate tumors varies with tumor grade. Cancer Res. 64: 6137.

Lyden D., Young A.Z., Zagzag D., Yan W., Gerald W., O'Reilly R., Bader B.L., Hynes R.O., Zhuang Y., Manova K., and Benezra R. 1999. Id1 and Id3 are required for neurogenesis, angiogenesis and vascularization of tumour xenografts. $\mathrm{Na}$ ture 401: 670.

Lyden D., Hattori K., Dias S., Costa C., Blaikie P., Butros L., Chadburn A., Heissig B., Marks W., Witte L., Wu Y., Hicklin D., Zhu Z., Hackett N.R., Crystal R.G., Moore M.A., Hajjar K.A., Manova K., Benezra R., and Rafii S. 2001. Impaired recruitment of bone-marrow-derived endothelial and hematopoietic precursor cells blocks tumor angiogenesis and growth. Nat. Med. 7: 1194.

Mabjeesh N.J., Post D.E., Willard M.T., Kaur B., Van Meir E.G., Simons J.W., and Zhong H. 2002. Geldanamycin induces degradation of hypoxia-inducible factor 1alpha protein via the proteosome pathway in prostate cancer cells. Cancer Res. 62: 2478.

Maisonpierre P.C., Suri C., Jones P.F., Bartunkova S., Wiegand S.J., Radziejewski C., Compton D., McClain J., Aldrich T.H., Papadopoulos N., Daly T.J., Davis S., Sato T.N., and Yancopoulos G.D. 1997. Angiopoietin-2, a natural antagonist for Tie2 that disrupts in vivo angiogenesis. Science 277: 55.

Manor D., Shmidt E.N., Budhu A., Flesken-Nikitin A., Zgola M., Page R., Nikitin A.Y., and Noy N. 2003. Mammary carcinoma suppression by cellular retinoic acid binding proteinII. Cancer Res. 63: 4426.

Neckers L. 2002. Heat shock protein 90 inhibition by 17-allylamino-17- demethoxygeldanamycin: A novel therapeutic approach for treating hormone-refractory prostate cancer. Clin. Cancer Res. 8: 962.

Nikolopoulos S.N., Blaikie P., Yoshioka T., Guo W., and Giancotti F.G. 2004. Integrin beta4 signaling promotes tumor angiogenesis. Cancer Cell 6: 471.

Perk J., Iavarone I., and Benezra R. 2005. The Id family of HLH proteins in cancer. Nat. Rev. Cancer 5: 603.

Pfeifer A., Kessler T., Silletti S., Cheresh D.A., and Verma I.M. 2000. Suppression of angiogenesis by lentiviral delivery of PEX, a noncatalytic fragment of matrix metalloproteinase 2. Proc. Natl. Acad. Sci. 97: 12227.

Ruzinova M.B. and Benezra R. 2003. Id proteins in development, cell cycle and cancer. Trends Cell Biol. 13: 410.

Ruzinova M.B., Schoer R.A., Gerald W., Egan J.E., Pandolfi P.P., Rafii S., Manova K., Mittal V., and Benezra R. 2003. Effect of angiogenesis inhibition by Id loss and the contribution of bone-marrow-derived endothelial cells in spontaneous murine tumors. Cancer Cell 4: 277.

Sacco M.G., Benedetti S., Duflot-Dancer A., Mesnil M., Bagnasco L., Strina D., Fasolo V., Villa A., Macchi P., Faranda S., Vezzoni P., and Finocchiaro G. 1996. Partial regression, yet incomplete eradication of mammary tumors in transgenic mice by retrovirally mediated HSVtk transfer 'in vivo'. Gene Ther. 3: 1151.

Shah N., Antony T., Haddad S., Amenta P., Shirahata A., Thomas T.J., and Thomas T. 1999. Antitumor effects of bis(ethyl)polyamine analogs on mammary tumor development in FVB/NTgN (MMTVneu) transgenic mice. Cancer Lett. 146: 15.

Slamon D.J., Clark G.M., Wong S.G., Levin W.J., Ullrich A., and McGuire W.L. 1987. Human breast cancer: Correlation of relapse and survival with amplification of the HER-2/neu oncogene. Science 235: 177. 
Slamon D.J., Leyland-Jones B., Shak S., Fuchs H., Paton V., Bajamonde A., Fleming T., Eiermann W., Wolter J., Pegram M., Baselga J., and Norton L. 2001. Use of chemotherapy plus a monoclonal antibody against HER2 for metastatic breast cancer that overexpresses HER2. N. Engl. J. Med. 344: 783.

Solit D.B., Zheng F.F., Drobnjak M., Munster P.N., Higgins B., Verbel D., Heller G., Tong W., Cordon-Cardo C., Agus D.B., Scher H.I., and Rosen N. 2002. 17-Allylamino-17demethoxygeldanamycin induces the degradation of androgen receptor and HER-2/neu and inhibits the growth of prostate cancer xenografts. Clin. Cancer Res. 8: 986.

Vogel C.L., Cobleigh M.A., Tripathy D., Gutheil J.C., Harris L.N., Fehrenbacher L., Slamon D.J., Murphy M., Novotny W.F., Burchmore M., Shak S., Stewart S.J., and Press M. 2002. Efficacy and safety of trastuzumab as a single agent in first-line treatment of HER2-overexpressing metastatic breast cancer. J. Clin. Oncol. 20: 719.

Yu J.L., Rak J.W., Coomber B.L., Hicklin D.J., and Kerbel R.S. 2002. Effect of p53 status on tumor response to antiangiogenic therapy. Science 295: 1526. 


\section{$8_{8}^{\infty} \mathrm{CSH} \&$ Cold Spring Harbor Symposia SYMPOSIA on Quantitative Biology}

\section{Induction of Complete Regressions of Oncogene-induced Breast Tumors in Mice}

R. BENEZRA, E. HENKE, A. CIARROCCHI, et al.

Cold Spring Harb Symp Quant Biol 2005 70: 375-381

Access the most recent version at doi:10.1101/sqb.2005.70.006

References This article cites 30 articles, 18 of which can be accessed free at: http://symposium.cshlp.org/content/70/375.full.html\#ref-list-1

License

Email Alerting Receive free email alerts when new articles cite this article - sign up in Service the box at the top right corner of the article or click here. 